\title{
Análise da qualidade da carne moída comercializada em um município no interior da Paraíba
}

\author{
Analysis of the quality of milled beef commercialized in a municipality in the interior of Paraíba \\ Análisis de la calidad de la carne molida comercializada en um municipio en el interior de Paraíba
}

Recebido: 22/03/2021 | Revisado: 28/03/2021 | Aceito: 31/03/2021 | Publicado: 10/04/2021

Joyce Almeida Lima

ORCID: https://orcid.org/0000-0002-5113-1903 Centro Universitário UniFacisa, Brasil

E-mail: joyce.lima@maisunifacisa.com.br

Ana Clara Bezerra Felinto

ORCID: https://orcid.org/0000-0002-5611-6948 Centro Universitário UniFacisa, Brasil

E-mail: anaclarabfelinto@gmail.com

Eduarda Josefa Alves Marçal

ORCID: https://orcid.org/0000-0003-0021-9144 Centro Universitário UniFacisa, Brasil E-mail: eduardamarca1826@gmail.com

Igor Macêdo de Oliveira

ORCID: https://orcid.org/0000-0003-3717-7291 Centro Universitário UniFacisa, Brasil E-mail: igormacedo1955@gmail.com

Juliana Barbosa de Sousa

ORCID: https://orcid.org/0000-0002-2228-8004 Centro Universitário UniFacisa, Brasil

E-mail: juliana.bs628@gmail.com Steffany Albuquerque do Bú

ORCID: https://orcid.org/0000-0002-4804-4657 Centro Universitário UniFacisa, Brasil

E-mail: steffanyalbuquerque12@gmail.com

Wagner Gomes de Melo

ORCID: https://orcid.org/0000-0001-5198-0457 Centro Universitário UniFacisa, Brasil E-mail: wagnerlegionario@hotmail.com

Mayra da Silva Cavalcanti

ORCID: https://orcid.org/0000-0003-1269-5324 Centro Universitário UniFacisa, Brasil

E-mail: mayra_cavallcanti@yahoo.com.br

\begin{abstract}
Resumo
A carne é um alimento muito importante para a população brasileira e seu setor econômico. O consumo de carne moída teve um grande aumento há três décadas, tanto em países desenvolvidos como nos em desenvolvimento, dado ao fato dela ser de baixo custo, além de uma forma melhor e mais conveniente de se aproveitar as carnes menos nobres. A presente pesquisa tencionou avaliar a qualidade higiênico-sanitária das carnes moídas comercializadas em uma cidade localizada no interior da Paraíba. Para tanto foram coletadas seis amostras deste tipo de carne em lugares distintos, ademais denotar os pontos de venda com contaminação. Para as análises físico-químicas foram testadas a atividade de água, a acidez, o $\mathrm{pH}$ e umidade do produto. Já para as análises microbiológicas foram seguidos os parâmetros recomendados pela legislação vigente. As amostras C, D, E e F atestaram presença para Salmonella spp. Para o grupo coliformes apenas as amostras $\mathrm{C}$, E e $\mathrm{F}$ acusaram risco para a presença destes, enquanto para Staplhylococcus aureus, todas as análises apresentaram negatividade. Quanto a caracterização físico-química os valores mostraram susceptibilidade dessas carnes a proliferação de bactérias, uma vez que a umidade se mostrou alta e o teor de acidez voltado para o neutro. Esse estudo mostra a importância de uma análise de controle de qualidade e segurança no consumo para essas carnes e invoca a necessidade de trabalho recorrente de boas práticas de manipulação com os comerciantes na tentativa de minimizar a contaminação.
\end{abstract}

Palavras-chave: Proteína; Microbiologia de alimentos; Análise físico-química.

\section{Abstract}

Meat is a very important food for the Brazilian population and its economic sector. The consumption of ground meat has increased dramatically three decades ago, both in developed and developing countries, given the fact that it is low cost, as well as a better and more convenient way to enjoy less noble meats. This research aimed to evaluate the 
hygienic-sanitary quality of ground meat sold in a city located in the interior of Paraíba. To this end, six samples of this type of meat were collected in different places, in addition to denoting points of sale with contamination. For physical-chemical analyzes, water activity, acidity, $\mathrm{pH}$ and humidity of the product were tested. For the microbiological analyzes, the parameters recommended by the current legislation were followed. Samples C, D, E and F confirmed their presence for Salmonella spp. For the coliform group, only samples C, E and F were at risk for their presence, while for Staplhylococcus aureus, all analyzes showed negativity. Regarding the physical-chemical characterization, the values showed susceptibility of these meats to the proliferation of bacteria, since the humidity was shown to be high and the acidity content turned to neutral. This study shows the importance of an analysis of quality control and safety in consumption for these meats and invokes the need for recurrent work of good handling practices with traders in an attempt to minimize contamination.

Keywords: Protein; Food microbiology; Chemical physical analysis.

\section{Resumen}

La carne es un alimento muy importante para la población brasileña y su sector económico. El consumo de carne picada ha aumentado dramáticamente hace tres décadas, tanto en países desarrollados como en desarrollo, dado que es de bajo costo, además de una forma mejor y más conveniente de disfrutar de carnes menos nobles. Esta investigación tuvo como objetivo evaluar la calidad higiénico-sanitaria de la carne picada comercializada en una ciudad ubicada en el interior de Paraíba. Para ello, se recolectaron seis muestras de este tipo de carne en diferentes lugares, además de denotar puntos de venta con contaminación. Para los análisis físico-químicos se ensayó la actividad del agua, la acidez, el pH y la humedad del producto. Para los análisis microbiológicos se siguieron los parámetros recomendados por la legislación vigente. Las muestras C, D, E y F confirmaron su presencia para Salmonella spp. Para el grupo de coliformes, solo las muestras C, E y F estuvieron en riesgo por su presencia, mientras que para Staplhylococcus aureus, todos los análisis mostraron negatividad. En cuanto a la caracterización físico-química, los valores mostraron susceptibilidad de estas carnes a la proliferación de bacterias, ya que la humedad se mostró alta y el contenido de acidez se volvió neutro. Este estudio muestra la importancia de un análisis de control de calidad y seguridad en el consumo de estas carnes e invoca la necesidad de un trabajo recurrente de buenas prácticas de manipulación con los comerciantes en un intento por minimizar la contaminación.

Palabras clave: Proteína; Microbiología alimentaria; Análisis físico químico.

\section{Introdução}

O Brasil é um dos mais importantes produtores de carne bovina do mundo, resultado de décadas de investimento em tecnologia que elevou a produtividade e a qualidade do produto brasileiro, favorecendo que se tornasse competitivo e chegasse ao mercado de mais de 150 países (Embrapa, 2020). No ano de 2019, as exportações de carne bovina representaram 2,4\% do total das exportações brasileiras, ou seja, um total de 1,84 milhões de toneladas (Abiec, 2019).

Este insumo é um alimento rico em proteínas, aminoácidos essenciais, além de gordura, vitaminas, glicídios e sais minerais como elementos nutritivos complementares. Assim, a carne se torna um maravilhoso substrato para o desenvolvimento e a proliferação de diversas espécies de microrganismos, requerendo cuidados especiais durante o processo produtivo de forma a garantir a suas propriedades e a saúde do consumidor (Diniz et al., 2013).

Estima-se uma evolução da produção da carne bovina, da suína e a de frango no país em mil toneladas. Observou-se que houve um aumento que passou de aproximadamente 6,6 milhões de toneladas em 2009 para 7,6 milhões de toneladas em 2017. A evolução da produção representou um crescimento médio de 1,7\% ao ano nesse período, medido pelo ajuste de uma função exponencial ao longo do tempo. O aumento na produção deste insumo envolve vários agentes atuando nos segmentos de cria, recria e engorda de forma exclusiva. Deste modo, os choques de demanda e oferta influenciam de forma significativa, já que se a procura cresce, o preço dos bezerros, do boi gordo e afins diminui o que facilita para os marchantes na comercialização da carne mais barata (Ipea, 2019).

Devido a essa vasta produção, houve fortalecimento dos programas de qualidade higiênico-sanitária no país e no mundo. Adequando assim, melhorias no manejo com os animais para redução da contaminação no campo, como também implantação de Boas Práticas de Fabricação (BPF), Procedimentos Padronizados de Higiene Operacional (PPHO) e sistema de Análise de Perigos e Pontos Críticos de Controle (APPCC). As carcaças bovinas ainda podem apresentar contaminações por microrganismos deteriorantes e patogênicos, originários de diversas fontes, torna-se necessário ampliar o controle de produção 
(Freire, 2014).

No entanto mesmo com todas as medidas preventivas, o Brasil sofre muito como abate clandestino, e mesmo existindo leis de inspeção Federal e Estadual é um problema recorrente devido à falta de fiscalização sanitária e por não incidir custos nestes estabelecimentos, relacionado aos impostos e taxas que deveriam ser pagas para fiscalização do local. As ilegalidades destes abatedouros trazem sérias consequências negativas para o consumidor, que acaba se alimentando de uma carne sem qualidade e sem nenhuma inspeção sanitária e segurança, oferecendo risco de Doenças Transmitidas por Alimentos (DTA) (Antunes et al., 2016).

Com a correria diária e o aumento considerável nos valores dos alimentos as pessoas têm buscado formas cada vez mais práticas e baratas para sua alimentação, não se atendo a critérios de segurança e procedência alimentar, seja por descuido ou quiçá condições financeiras, estando dessa forma mais susceptíveis a patógenos (Reis, 2019).

Entre os derivados deste alimento, a carne moída é um subproduto que se revela entre os demais. Esta é o produto cárneo obtido a partir da moagem de massas musculares de carcaças de bovinos, seguido de imediato resfriamento ou congelamento (Brasil, 2003). A carne moída possui uma alta capacidade de propagação de patógenos, por ser adquirida de outros pedaços de carnes já manuseadas, ademais, à exposição em temperatura inadequada, alta atividade de água e pH oportuno. Todos estes fatores resultam na facilidade de contaminação por patógenos como a Salmonella, Stapylococcus aureus e a Escherichia coli (Gomes et al., 2017).

Estatísticas da Organização Mundial de Saúde (OMS) comprovam que as DOA’s são consideradas o maior problema de saúde pública em todo o mundo, sendo os manipuladores referenciados como um dos principais veículos de contaminação, tendo em vista que sua participação chega a atingir até $26 \%$ das fontes contaminantes (Sousa et al., 2012).

Diante do exposto existe uma necessidade no controle da qualidade da carne moída comercializada em açougues, supermercados e feiras livres, principalmente em cidades do interior. Pensando nisto, o presente trabalho tencionou avaliar a qualidade higiênico-sanitária das carnes moídas comercializadas em uma cidade no interior da Paraíba, foram coletadas seis amostras de carne moída em lugares distintos, ademais denotar os pontos de venda com contaminação.

\section{Metodologia}

As carnes moídas foram adquiridas no município de Barra de Santa Rosa (PB, Brasil), por meio de fornecedores locais de feiras livres e em estabelecimentos comerciais. O preparo das amostras e as análises físico-químicas foram realizadas no Laboratório de Farmacologia e Bromatologia e as análises microbiológicas foram realizadas no laboratório de Microbiologia e Imunologia todos localizados no Centro Universitário - UniFacisa, na cidade de Campina Grande (PB, Brasil).

As carnes foram adquiridas nos estabelecimentos comerciais da cidade supracitada. Foram compradas numa porção de 200g e separadas em dois sacos de100g, onde um foi direcionado a análise Bromatológica e o outro a Microbiológica com o intuito de reduzir os possíveis vieses. Posteriormente, foi realizado o acondicionamento em caixa térmica com gelo para o transporte ao local de análise.

Os procedimentos de análises ocorreram entre o período de setembro a outubro de 2020, seguindo a Instrução Normativa $N^{\circ}$ 62/2003 do Ministério da Agricultura, Pecuária e Abastecimento (MAPA) para os requisitos de qualidade (Brasil, 2003).

\subsection{Análise microbiológica}

Os coliformes totais foram pressupostos pela utilização da técnica do número mais provável (NMP). Assim, foi utilizado o método de análise para contagem proposto por Silva et al. (2017) para determinação deste microrganismo em 
alimentos e água. Para isso, foi aplicada a técnica dos tubos múltiplos com preparação de diluições até a $10^{-3}$ em água peptonada tamponada. Assim, 2,5g da amostra foram transferidas para 22,5ml de água peptonada perfazendo a diluição $10^{-1}$. As diluições seguintes forma feitas com a retirada de $1 \mathrm{ml}$ da diluição anterior para $9,0 \mathrm{ml}$ de água peptonada até a diluição $10^{-3}$.

As alíquotas das diluições foram transferidas para tubos contendo Caldo Verde Brilhante (CLBVB) que permite a fermentação do grupo de coliformes, em triplicata. Os tubos de CLBVB foram incubados em estufa bacteriológica a $37^{\circ} \mathrm{C}( \pm 2)$ por 24 a 48 horas, sendo considerados positivos os tubos que apresentaram turvação e formação de gás, como possível de visualizar na Figura 1.

Figura 1. Tubos de CLBVB com formação positiva de gás.

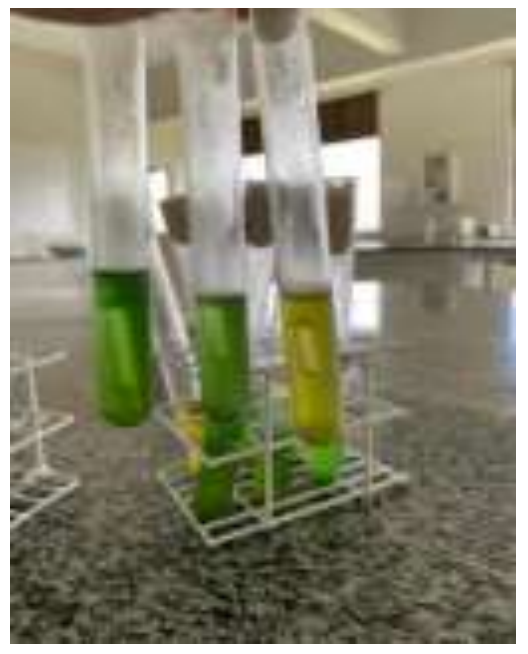

Fonte: Autores (2020).

A detecção de Staphylococcus foi baseada na metodologia descrita por Resta e Oliveira (2013). Para isso, uma alíquota de 2,5g de cada amostra do alimento foram pesadas em condições assépticas e posteriormente homogeneizadas com $22,5 \mathrm{ml}$ de água peptonada $0,1 \%$. Passado um período entre 30 a 60 minutos sob refrigeração, as amostras foram homogeneizadas. Foram realizadas diluições decimais, a partir da diluição $10^{-1}$, preparadas em tubos contendo 9,0ml de água peptonada $0,1 \%$ estéril, até a diluição de $10^{-3}$. Alíquotas de $0,1 \mathrm{ml}$ das diluições foram semeadas em ágar Vogel e Johnson em duplicata. As placas foram incubadas a $35^{\circ} \mathrm{C}( \pm 2)$ e, após 48horas, realizadas a identificação e a contagem das colônias que apresentarem as características típicas de Staphylococcus spp. Em meio de cultivo Agar Volgel-Johnson, apresentavam-se negras, pequenas e com halo amarelo.

Para tanto, foi utilizado o Método da AOAC (2016) sugerido por Silva et al. (2017) para presença e ausência de Salmonella em alimentos. Este método é aplicado para todos os alimentos de consumo humano. A amostra foi inicialmente diluída em água peptonada para pré-enriquecimento; onde posteriormente foi mantida em repouso a $35^{\circ} \mathrm{C}\left( \pm 1^{\circ}\right)$ por 18 horas $( \pm 2)$. Após esse período, $1 \mathrm{ml}$ do conteúdo foi transferido para o caldo de Tetrionato e incubada à $37^{\circ} \mathrm{C}\left( \pm 1^{\circ}\right)$ por 24 horas $( \pm 3)$. Passado o período, o conteúdo foi transferido para os meios de Ágar Bismuto Sulfito (BS) e Ágar Entérico de Hectoen (HE) em alíquotas de $0,1 \mathrm{ml}$, utilizando-se da técnica de esgotamento em superfície, onde foi novamente incubada a $37^{\circ} \mathrm{C}\left( \pm 1^{\circ}\right)$ por24horas $( \pm 3)$. As colônias típicas no Ágar HE eram verde-azuladas, transparentes, com ou sem centro preto, e as apresentadas no Ágar BS eram colônias cinza ou pretas, castanhas, com ou sem brilho metálico.

\subsection{Análises físico-químicas}

A atividade de água foi determinada através de leitura direta da amostra em temperatura de aproximadamente $25^{\circ} \mathrm{C}$, 
em higrômetro Aqualab®, modelo 3TE, fabricado pela Decagon.

$\mathrm{O}$ pH foi determinado pelo método potenciométrico, com medidor digital modeloTEC-2, do fabricante Tecnal, calibrado com soluções tampão de pH 4,0 e 7,0 de acordo com metodologia descrita por IAL (2008). Os resultados serão expressos em unidades de pH. A carne foi classificada em: boa para consumo (PH 5,8 a 6,2); apenas para consumo imediato, limite crítico (PH 6,4); início de decomposição (pH acima de 6,4).

A umidade das carnes foi determinada de acordo com metodologia do IAL (2008). Os cadinhos foram antecipadamente secos em estufa a $105^{\circ} \mathrm{C}$ por 24 horas. Posteriormente, foram pesadas de 2 a 5 gramas da amostra em cadinho previamente tarado. Sendo incineradas em forno mufla, aquecido a $550^{\circ} \mathrm{C}$, até a obtenção de um resíduo isento de carvão, com coloração branca acinzentada. Logo após, as amostras foram resfriadas em dessecador até a temperatura ambiente, e pesada até ter peso constante.

Foi determinada pelo método títulométrico, que se baseia na neutralização dos íons H+ com a solução de hidróxido de sódio $(\mathrm{NaOH})$ 0,1 N, padronizada com ácido oxálico, como titulante (IAL, 2008).

\subsection{Tratamento dos dados estátisticos}

Para a avaliação dos resultados referentes às análises físico-químicas foi aplicada a Análise de Variância (ANOVA) e teste de Tukey, utilizando o nível de significância de 5\%, para comparação das médias. Para o cálculo destes dados, utilizou-se o programa - Statistics Analys Systems, versão 8.12 (SAS, 1999).

\section{Resultados e Discussão}

Os resultados obtidos nesta pesquisa para as análises microbiológicas das amostras de carnes moídas estão demonstrados na Tabela 1.

Tabela 1. Avaliação da qualidade higiênico sanitária das carnes moídas comercializadas no município de Barra de Santa Rosa $-\mathrm{PB}$.

\begin{tabular}{cccc}
\hline \multirow{2}{*}{ CARNE MOÍDA } & \multicolumn{3}{c}{ ANÁLISES } \\
\cline { 2 - 4 } & Salmonella $(\mathrm{UFC} / \mathrm{g})$ & Staphylococcus aureus $(\mathrm{UFC} / \mathrm{g})$ & Coliformes totais à $35^{\circ} \mathrm{C}$ (NMP/g) \\
\hline A & Ausente & Ausente & $>1,1 \times 10^{3}$ \\
B & Ausente & Ausente & $>1,1 \times 10^{3}$ \\
C & Presente & Ausente & $<3,0$ \\
D & Presente & Ausente & $>1,1 \times 10^{3}$ \\
E & Presente & Ausente & $2,3 \times 10^{1}$ \\
F & Presente & Ausente & 3,6 \\
\hline
\end{tabular}

Fonte: Autores (2020).

As amostras C, D, E e F apresentaram positividade para o microrganismo Salmonella spp. No estudo de Queiroz, (2017) foram realizadas duas coletas de amostras de carne moída e os resultados quanto a presença/ausência de Salmonella spp. indicou que em das 106 amostras analisadas na $1^{\circ}$ coleta, $11(10,4 \%)$ foram positivas para Salmonella spp., enquanto na $2^{\circ}$ etapa foram $24(23,76 \%)$ positivas. Assim, o número de Salmonella spp. na $2^{\circ}$ coleta aumentou consideravelmente. Esse aumento pode estar relacionado a falhas nas etapas de abate, transporte, manipulação e refrigeração.

Salmonella spp. é encontrada predominantemente no intestino de animais de produção. Estando associada ao consumo de carnes e derivados. A salmonelose é uma das toxinfecções mais comuns provenientes da contaminação por soro tipos paratifoides da Salmonella spp. (Filho et. al., 2014; Silva et al., 2018). Trata-se de uma das principais zoonoses 
responsáveis por transtornos de saúde pública no mundo e a sua evidente importância como patógeno requer a necessidade de legislação e medidas específicas, onde há inviabilização do consumo e comercialização de produtos em que haja o isolamento de Salmonella, bem como o controle de sua transmissão (Silva et al., 2018).

No Brasil, a Secretaria de Vigilância em Saúde do Ministério da Saúde, entre os anos de 2007 e 2017, notificaram ao Ministério da Saúde em 6.632 surtos de Doenças Transmitidas por Alimentos (DTA). No total, 118.104 pessoas adoeceram. Entre os agentes envolvidos 90,5\% envolve bactérias, em primeiro lugar a Salmonella (7,5\%) (Brasil, 2016). O que desta forma, intensifica a positividade dessa zoonose em outros estudos a nível nacional.

Já para Stapylococcus aureus todas as amostras obtiveram resultados negativos para presença do microrganismo. A resolução vigente não padroniza limite para este patógeno em carne moída, mas determina para produtos cárneos crus, refrigerados ou congelados numa contagem máxima de 5,0 x 10³ UFC/g (Brasil, 2003).

A intoxicação alimentar por Stapylococcus é uma das mais comuns em alimentos e acontece pela ingestão de toxinas pré-formadas produzidas pelo microrganismo em alimentos (Hennekinne; Buyser \& Dragacci, 2012). A doença transmitida por este é classificada no grupo de risco III pela International Commissionon Microbiological Specifications for Foods, onde estão as patologias de perigo moderado, de curta duração e sem ameaça de vida ou sequelas, com sintomas que causam desconforto severo (Silva et al., 2017).

Diferente do presente estudo, Silva et al. (2020) em seus estudos com carne moída bovina comercializada em açougues dos mercados de Itapetinga- BA, encontraram a presença deste microrganismo em todas as suas amostras. Já Monteiro et al. (2018), encontraram presença de Stapylococcus aureus em $87 \%$ de suas amostras de carnes moídas comercializadas em supermercados do Distrito Federal.

A legislação brasileira não estabelece limites de tolerância para o grupo dos coliformes totais em carne moída, porém, a presença desse microrganismo indica condições higiênicos-sanitárias deficientes, provavelmente decorrentes de diversas etapas da produção, colocando em risco a saúde dos consumidores (Rosina \& Monego, 2013).

Observou-se a presença de coliformes totais a $35^{\circ} \mathrm{C}$ em alguns dos tratamentos, com resultado superior a $2,3 \times 10^{1} \mathrm{em}$ $50 \%$ das amostras (A, B, D). A partir de um estudo realizado por Queiroz (2017), pode-se observar que das amostras de carne moída bovina vendidas no comércio de Araguaína -TO, na $1^{\circ}$ etapa de análise foram encontrados valores acima de $10^{5} \mathrm{UFC} / \mathrm{g}$, enquanto na $2^{\circ}$ coleta foram $38,61 \%$ das amostras acima de $10^{5} \mathrm{UFC} / \mathrm{g}$. Delimitando que na $2^{\circ}$ coleta as carnes estavam com mais tempo de prateleira, significando que estavam mais próximas do período de vencimento ou até mesmo deterioradas.

Darmer, Huppes e Moresco (2016) obtiveram em seu estudo resultados para coliformes totais de 100\% (31/31) das amostras de carne moída in natura, bem como os coliformes termotolerantes. A grande maioria das amostras resultou em contagens que ficaram acima do limite detectado pelo método, em $83,87 \%$ (26/31) para as contagens de coliformes totais e $58,06 \%$ (18/31) para as contagens de coliformes termotolerantes.

A partir de estudo realizado por Antunes et al. (2016), entre as 15 amostras dos cortes avaliados, 86,7\% apresentaram resultados positivos para o teste presuntivo de coliformes totais e 86,7\% (13) apresentaram-se positivas para o teste confirmativo de coliformes totais. Concluindo que apesar da presença de coliformes totais nas amostras de carnes analisadas não ser, necessariamente, indicador de alimento inseguro, o fato de as condições serem insatisfatórias pode trazer riscos para a população que está exposta a consumir a carne bovina comercializada nos açougues do município, podendo ocasionar as DOA's.

De uma forma geral, nas análises microbiológicas das amostras C, D, E e F mostraram presença para Salmonella spp., estando assim fora do padrão estabelecido pela legislação para qualidade da carne. Enquanto, para Staplhylococcus aureus todas se mostraram ausentes. Para Coliformes apenas as amostras C, E e F acusam risco para a presença destes. Visto a importância de atender esse parâmetro, pois muitas doenças são oportunistas e causadas por questões de consumo de alimentos 
contaminados pela má manipulação da carne desde o abate até a mesa do consumidor.

\subsection{Análises físico-químicas}

Os resultados obtidos para as análises físico-química das carnes moídas comercializadas no município de Barra de Santa Rosa são demonstrados na Tabela 2. Pelas os dados podemos afirmar que quanto ao teor de acidez as amostras A, B, C e D, demonstraram resultados insatisfatórios para os níveis de acidez, mostrando que as carnes desses estabelecimentos estão totalmente fora do padrão de qualidade para consumo. Enquanto, que as amostras E e F mostram-se com acidez desejável.

Tabela 2. Valores médios das variáveis físico-químicas das amostras de carne moída comercializadas em estabelecimentos no município de Barra de Santa Rosa, PB.

\begin{tabular}{ccccc}
\hline CARNE MOÍDA & \multicolumn{4}{c}{ VARIÁVEIS } \\
\cline { 2 - 5 } & Atividade de água (Aa) & $\mathrm{pH}$ & Umidade $(\mathrm{g} / 100 \mathrm{~g})$ & Acidez $(\mathrm{g} / 100 \mathrm{~g})$ \\
\hline A & $0,889^{\mathrm{b}}$ & $5,61 \pm 0,05^{\mathrm{b}}$ & $98,17 \pm 0,61^{\mathrm{a}}$ & $7,78 \pm 0,55^{\mathrm{b}}$ \\
B & $0,893^{\mathrm{a}}$ & $5,47 \pm 0,24^{\mathrm{b}}$ & $98,22 \pm 0,59^{\mathrm{a}}$ & $8,89 \pm 0,73^{\mathrm{b}}$ \\
C & $0,893^{\mathrm{a}}$ & $5,87 \pm 0,01^{\mathrm{b}}$ & $90,80 \pm 0,75^{\mathrm{b}}$ & $11,75 \pm 0,27^{\mathrm{a}}$ \\
D & $0,881^{\mathrm{c}}$ & $6,27 \pm 0,01^{\mathrm{a}}$ & $73,10 \pm 0,45^{\mathrm{c}}$ & $8,25 \pm 0,55^{\mathrm{b}}$ \\
E & $0,889^{\mathrm{b}}$ & $6,44 \pm 0,01^{\mathrm{a}}$ & $74,42 \pm 0,79^{\mathrm{c}}$ & $3,33 \pm 0,00^{\mathrm{c}}$ \\
F & $0,889^{\mathrm{b}}$ & $5,73 \pm 0,00^{\mathrm{b}}$ & $72,46 \pm 0,58^{\mathrm{c}}$ & $3,17 \pm 0,27^{\mathrm{c}}$ \\
\hline
\end{tabular}

a-c Média \pm desvio-padrão com letras minúsculas diferentes na mesma coluna diferiram entre si pelo teste de Tukey (p<0,05) entre os tratamentos. Fonte: Autores (2020).

Bonacina, Biancini e Da Rosa (2019) realizaram uma pesquisa semelhante à nossa, e os valores de acidez obtidos variaram entre $(3,53,5,26$ e 6,95$)$ para os estabelecimentos A, B e C, respectivamente. A autora justifica os valores de acidez de sua pesquisa a partir do potencial redox (Eh) realizado, pois quanto maior o potencial redox maior a disponibilidade de oxigênio no produto, e vice e versa.

Nossas amostras demonstraram resultados elevados para acidez, (A, B, C e D), sendo justificado pela quantidade de água das amostras, apresentando umidade acima de 70\%, extrapolando os valores ideais, mostrando dessa forma uma alteração das carnes desses estabelecimentos, sendo consideradas fora do padrão de qualidade para consumo.

Os valores de atividade de água nas diferentes amostras estavam entre 0,881 e 0,893 , apresentando dessa forma uma diferença significativa, entre as medias obtidas, com o valor menor do estabelecimento D e os maiores dos estabelecimentos B e C. A atividade de água elevada favorece o desenvolvimento de microrganismos patogênicos causadores de toxinfecções, como salmoneloses. As bactérias patogênicas crescem em atividade de água acima de 0,85 (Jay, 2005; Koblitz, 2011; Ordóñez, 2005). O que indica que as carnes analisadas estão propensas ao ataque bacteriano.

Corroborando para os resultados do atual estudo, Gavião et al. (2018) obtiveram resultados médios de 0,99 para atividade de água em suas nove amostras estudadas, indicando que todas possuíam nível alto de atividade de água, o que colabora para a proliferação de microrganismos.

Para os valores de $\mathrm{pH}$ as amostras se mostraram mais próximo do básico o que sinaliza propensão ao desenvolvimento de microrganismos patogênicos. As amostras D e E são as mais propensas, pois os pH ficaram com 6,27 e 6,44, respectivamente. De acordo com a Portaria $\mathrm{n}^{\circ} 1$, de 7 de outubro de 1981, a carne é dita como ideal para o consumo quando apresentar valores entre 5,8 e 6,2. No entanto, o consumo deve ser imediato quando em pH 6,4 e valores acima, a carne é considerada imprópria para o consumo por indicar início de decomposição (Brasil, 1981), observando-se que a amostra E excedeu esse valor, podendo ser assim considerada imprópria.

Gavião et al. (2018) ao analisar carne moídas do comercio local de Itaqui, RS, encontraram pH variando entre 5,5 e 
6,0. Assim, os mesmos concluíram que nenhuma das amostras apresentou indícios de decomposição relacionados ao pH, mas em contrapartida, o pH de 3,3\% destas não estava na classificação anterior de carne apta ao consumo.

Duarte (2017) em sua pesquisa, encontrou valores parecidos com os obtidos com a nossa (6,01 e 6,31) que também coincidem com os valores apontados como valores ideias para o consumo de carne (5,8 e 6,2) de acordo com Brasil (1981). É importante ressaltar que a composição físico-química da carne faz com que a mesma se torne um meio de cultura para o crescimento de microrganismos, por apresentar características como elevada atividade de água (em torno de 75\%) e pH próximo ao neutro, além de ser suscetível a modificações de ordem física e química (Ferreira \& Simm, 2012; Hangui et al., 2015).

Em decorrência do $\mathrm{pH}$ alto, as proteínas musculares conservam grande capacidade para reter água no interior das células e, como consequência, a superfície de corte do músculo permanece pegajosa e escura (Petrolini, 2014). Alterações no sabor, odor, cor, estabilidade e manutenção da qualidade podem ser decorrentes de ácidos orgânicos presentes nas carnes, bem como sua presença pode indicar deterioração por bactérias com produção de ácidos (Bonacina; Biancini \& Da Rosa, 2019).

Em relação ao conteúdo de umidade, a carne bovina apresenta em média 75\%de água, variando-se entre 65 e $80 \%$ (Souza et al., 2008). Tais valores estão um pouco abaixo dos valores das amostras A, B e C que obtiveram um percentual próximo de $90 \%$ ou mais, enquanto as amostras $\mathrm{D}, \mathrm{E}$ e $\mathrm{F}$ apresentaram-se dentro dos padrões, com valores pouco maiores que $70 \%$.

Contudo, das seis amostras de carne moída comercializadas apenas os estabelecimentos A e B, atendem o preconizado para as características microbiológicas para qualidade da carne, já os outros apresentaram resultados insatisfatórios em algum dos itens avaliados podendo gerar riscos de contaminação ao consumidor. Quanto a caracterização físico-química de pH, ATT, umidade e atividade de água, os valores mostraram sustentabilidade dessas carnes a proliferação de bactérias, uma vez que a umidade se mostrou alta e o teor de acidez voltado para o neutro. É muito importante todas as amostras atenderem a legislação preconizada, sendo a garantia de carnes para consumo com mais segurança e qualidade.

\section{Conclusão}

Visto a importância do controle, manutenção e segurança, é notória a relevância dos resultados obtidos a partir dos parâmetros avaliados, tendo em vista o apontamento de indicadores de doenças. Sendo estas consideradas em sua maioria oportunistas e que agem de forma silenciosa, através do consumo de alimentos contaminados pela má manipulação da carne desde o abate causando prejuízos a saúde do consumidor.

A presença de Salmonella spp. em quatro dos seis estabelecimentos, causa uma alerta para o desenvolvimento de práticas sanitárias minuciosas, tendo em vista que esse patógeno é responsável por toxinfecções sérias. Dentro das leis de saúde públicas sanitárias e de controle de qualidade, o perfil dessas carnes comercializadas no município de Barra de Santa Rosa, em decorrência da procura semanal, precisa ser revisto, já que a demanda de compra e venda é presente de maneira assídua pelos comerciantes e sociedade civil. Assim, buscar parcerias com a prefeitura e demais instituições locais para realização de uma educação sanitária, criações de projetos educativos municipais servem como meio de conscientização para a população, a fim de informar a comunidade sobre os possíveis riscos de ocorrência de doença com o consumo de carnes sem controle de qualidade, e orientar sobre os riscos à saúde, se torna importante, ademais buscar órgãos responsáveis pela fiscalização para os comércios. Também são necessárias mais pesquisas para comprovar os dados encontrados e tentar sanar tal risco de saúde, além de um trabalho constante de orientação para as boas práticas de manipulação e venda. 


\section{Referências}

Abiec. (2019). Volume exportado de carne bovina cresceu 9,2\% de janeiro a setembro de 2019 . $\underline{\text { http://abiec.com.br/dow }}$ nload/release_exportacoes_janeiro\%20a\%20setembro2019.

Antunes, A. R., Oliveira, G. L., Salema, R. B., \& Souza, L. T. D. (2016). Pesquisa de coliformes em carne bovina comercializada no município do Vale do Jequitinhonha MG. Higiene Alimentar, 30(256/257), 82-86.

Bonacina, M. S., Biancini, M. B., \& Souza, L. S. (2019). Avaliação da qualidade oxidativa e segurança microbiológica da carne de frango comercializadas em Erechim-RS.

Brasil (1981). Métodos Analíticos para Controle de Produtos de Origem Animal e Seus Ingredientes. Diário Oficial da União. Brasília.

Brasil (2003). Instrução Normativa no83, de 21 de novembro de 2003. Aprova os regulamentos técnicos de identidade e qualidade de carne bovina em conserva e carne moída de bovino. Brasília: Ministério da Agricultura, Pecuária e Abastecimento.

Brasil (2016). Unidade de Vigilância das Doenças de Transmissão Hídrica e Alimentar. Brasília: Ministério da Saúde. Secretaria de Vigilância em Saúde.

Damer, J. R. S., Huppes, A. T., \& Moresco, T. R. (2016). Qualidade higiênico-sanitária de carne moída in natura comercializada no norte do Rio Grande do Sul-Brasil. Revista de Ciências Farmacêuticas Básica e Aplicada, 37(1).

Diniz, W. J. da S. et al. (2013) Aspectos higiênicos da comercialização de carnes em feiras livres: a percepção do comerciante. Revista Acta Veterinaria Basílica. 4 (7), 294-299.

Duarte, K. C. G. (2017). Avaliação microbiológica de carne moída comercializada no mercado central de Teresina-PI. (Trabalho de conclusão de curso). Instituto Federal de Educação, Ciência e Tecnologia do Piauí. Teresina, PI, Brasil.

Embrapa. (2020). Qualidade da carne bovina. https://www.embrapa.br/qualidade-da-carne/carne-bovina.

Ferreira, R. S., \& Simm E. M. (2012). Análise microbiológica da carne moída de um açougue da região central do município de Pará de Minas/ MG. Revista Digital Fapam, 3 (3): 37- 61.

Filho, V. J. R. G., et al. (2014). Investigation of Salmonella spp. in backyard chickens (Gallus gallusdomesticus) and eggs sold in free markets in the city of Fortaleza, Ceará. Semina: Ciências Agrárias, 35(4), 1855-1864.

Freire, M. C. F. B. (2014). Avaliação da qualidade microbiológica de cortes de cárneos bovinos desossados sob diferentes temperaturas. (Tese de Doutorado). Universidade Federal de Goiás. Programa de Pós-Graduação em Ciências Animal. Goiânia, GO, Brasil.

Gavião, E. R., Nespolo, C. R., Munieweg, F. R., Ferreira, M. B., Pinheiro, F. C., Pinheiro, F. C., \& Soares, G. M. (2018). Qualidade microbiológica de carne moída de bovino resfriada e comercializada em Itaqui, RS. Revista Brasileira de Produtos Agroindustriais, 20(1), 1-10.

Gomes, A. D. F. A., Almeida, E. E. S., de Souza, S. A., Silva, J. P., Santos, C. C., Amâncio, T. A., \& Farias, P. K. S. (2017). Avaliação microbiológica de carnes moídas bovinas em diferentes estabelecimentos comerciais/Microbiological evaluation of bovine ground meat in different commercial establishments. Caderno de Ciências Agrárias, 9(3), 95-100.

Hangui S. A. R. et al. (2015). Análise microbiológica da carne bovina moída comercializada na cidade de Anápolis, Goiás, Brasil. Revista Eletrônica de Farmácia, v. 12, n. 2, p. 30- 38.

Hennekinne, J. A., De Buyser, M. L., \& Dragacci, S. (2012). Staphylococcus aureus and its food poisoning toxins: characterization and outbreak investigation. FEMS microbiology reviews, 36(4), 815-836.

Ial. (2008). Normas analíticas do IAL: métodos químicos e físicos para análise de alimentos. (5a ed.), Instituto Adolfo Lutz. Brasil.

Ipea. Instituto de Pesquisa Econômica Aplicada. (2019). Inserção no mercado internacional e a produção de carnes no Brasil.

Jay, J. M. (2005). Microbiologia de Alimentos. (6a ed.), Artmed, p. 712.

Koblitz, M. G. B. (2011). Matérias-primas Alimentícias: Composição e controle de qualidade. Guanabara Koogan, p. 320.

Monteiro, E. S. et al. Qualidade microbiológica de carne bovina moída comercializada em supermercados do Distrito Federal, Brasil. Revista Brasileira de Higiene e Sanidade Animal, 12(4): 520 - 530, 2018.

Ordóñez, J. A (2005). Tecnologia de Alimentos: Alimentos de Origem Animal. 2, 280.

Petrolini, S. M. (2014). Influência do bem-estar animal na qualidade da carne bovina. Ituverava

Queiroz, I. K. A. (2017). Carne moída bovina em Araguaína: qualidade higiênico-sanitária e perfil de resistência antimicrobiana de E. coli e Salmonella $s p$ (Dissertação de Mestrado). Universidade Federal de Tocantins. Programa de Pós-Graduação em Ciência Animal Tropical.

Reis, R. M. D. (2019). Qualidade de carne bovina moída" in natura" comercializada em Manaus, AM. (Dissertação de Mestrado). Universidade Federal do Amazonas. Programa de Pós-Graduação em Ciências Animal.

Resta, M. S. A., \& Oliveira, T. C. R. M. D. (2013). Avaliação do padrão estafilococos coagulase positiva estabelecido pela legislação brasileira para massas alimentícias. Brazilian Journal of Food Technology, 16(4), 319-325. 
Research, Society and Development, v. 10, n. 4, e27610414148, 2021

(CC BY 4.0) | ISSN 2525-3409 | DOI: http://dx.doi.org/10.33448/rsd-v10i4.14148

Rosina, A., \& Monego, F. (2013). Avaliação microbiológica da carne bovina moída nas redes de supermercados de Canoinhas/SC. Saúde e meio ambiente: revista interdisciplinar, 2(2), 55-64.

SAS. (1999). SAS/STAT user's guide. Version 8, 2. Cary, N.C., USA, SAS Publishing, 634 p.

Silva, N., et al. (2017). Manual de métodos de análises microbiológica de alimentos e água. (5a ed.), Blucher.

Silva, A. J. H. et al. (2018) Salmonella spp. um agente patogênico veiculado em alimentos. In: XIII Encontro de Extensão, Docência e Iniciação Científica. 5(1). Anais, Quixada, CE.

Silva, D. de F., et al. (2020). Microbiological analysis of ground beef sold at butchers in markets of Itapetinga - BA. Research, Society and Development, 9(1), 35911513.

Souza. J. M. et al. (2008). Determinação dos teores de umidade e proteína em carne charque. In: Congresso Brasileiro De Química, 48, 2008, Anais, 1-3.

Sousa, C. O. et al. (2012). Perfil da qualidade higiênico- sanitária de carnes comercializadas em férias livres do município de Pau dos Ferros/RN - Brasil. http://propi.ifto.edu.br/ocs/index.php/connepi/vii/paper/viewFile/1674/2866. 